\title{
Corrigendum: Randomized, crossover questionnaire survey of acceptabilities of controlled-release mesalazine tablets and granules in ulcerative colitis patients
}

Keiji Yagisawa ${ }^{1}$, Taku Kobayashi ${ }^{2}$, Ryo Ozaki ${ }^{2}$, Shinji Okabayashi ${ }^{2}$, Takahiko Toyonaga ${ }^{2}$, Miki Miura ${ }^{3}$, Mari Hayashida ${ }^{3}$, Eiko Saito ${ }^{2}$, Masaru Nakano ${ }^{2}$, Hajime Matsubara ${ }^{1}$, Tadakazu Hisamatsu ${ }^{3}$, Toshifumi Hibi ${ }^{2}$

${ }^{1}$ Department of Pharmacy and ${ }^{2}$ Center for Advanced IBD Research and Treatment, Kitasato University Kitasato Institute Hospital, Tokyo; ${ }^{3}$ The Third Department of Internal Medicine, Kyorin University School of Medicine, Tokyo, Japan

https://doi.org/10.5217/ir.2018.00078

Intest Res 2019;17(1):87-93

In the version of this article initially published, Figure 2 contains errors in the content of the questionnaire.

On page 89, the figure should be corrected as following.

\section{From:}

\section{A}

Questionnaire 1 (about usability of the tablet)

Q I. Did you feel the tablets were hard to take?

Q II. In case you answered "yes" in Q I, why? (multiple answers are allowed)

$\begin{array}{lll}\text { 1. Size of the tablet } \quad \text { 2. Pill number } \quad \text { 3. Frequency } & \end{array}$

4. I do not like tablets not limited to the CR mesalazine $\quad 5$. Tastes

6. Portability 7. The other reason

Q III. How much percentage of dose did you take correctly?

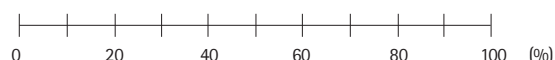

Q IV. Have you missed the doses once or more often because of the usability of the tablets?

B Questionnaire 2 (on the usability of the granules)

Q I. Did you feel the granules were hard to take?

Q II. In case you answered "yes" in Q I, why? (multiple answers are allowed)

1. Volume of the granules $\quad$ 2. Sachet number $\quad$ 3. Frequency

4. I do not like granules not limited to the CR mesalazine 5. Tastes

6. Portability 7. The other reason

Q III. How much percentage of dose did you take correctly?

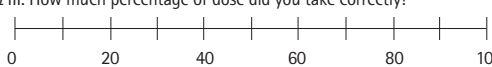

Q IV. Have you missed the doses once or more often because of the usability of the granules?
C Questionnaire 3 (on comparison of the tablets and the granules)

Q I. Which formulation did you feel easier to take?

QII. In case you answered "tablet" in 0 I. why? (multiple answers are allowed)

1. The volume of the granules was large

2. The sachet number of the granules was large

3. Taking granules is harder than tablets regardless of products

4. The tablets taste or smell better than the granules.

5. The tablets are easier to carry than the granules.

6. The other reason

Q III. In case you answered "granules" in Q I. why?

1. The size of the tablet is big

2. The tablet number is large

3. Taking granules is harder than tablets regardless of products

4. The granules taste or smell better than the tablets

5. The granules are easier to carry than the tablets

6. The other reason

QV. Which formulation did you feel more effective?

Fig. 2. (A) Questionnaire 1: acceptability of tablets. (B) Questionnaire 2: acceptability of granules. (C) Questionnaire 3: comparison of tablets and granules. All the original questionnaires were written in Japanese. CR, controlled-release. 
To:

A

Questionnaire 1 (about usability of the tablet)

Q I. Did you feel the tablets were hard to take?

Q II. In case you answered "yes" in 0 I, why? (multiple answers are allowed)

1. Size of the tablet 2. Pill number 3. Frequency

4. I do not like tablets not limited to the CR mesalazine 5. Tastes

6. Portability

7. The other reason

0 III. How much percentage of dose did you take correctly?

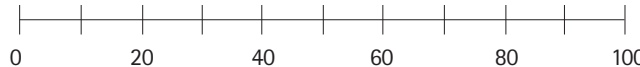

Q IV. Have you missed the doses once or more often because of the usability of the tablets?

B Questionnaire 2 (on the usability of the granules)

Q I. Did you feel the granules were hard to take?

Q II. In case you answered "yes" in $0 \mathrm{I}$, why? (multiple answers are allowed)

1. Volume of the granules $\quad 2$. Sachet number $\quad 3$. Frequency

4. I do not like granules not limited to the CR mesalazine 5. Tastes

6. Portability 7. The other reason

Q III. How much percentage of dose did you take correctly?

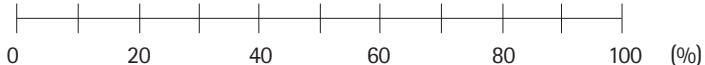

Q IV. Have you missed the doses once or more often because of the usability of the granules?
C

Questionnaire 3 (on comparison of the tablets and the granules)

Q I. Which formulation did you feel easier to take?

Q II. In case you answered "tablet" in 0 I. why? (multiple answers are allowed)

1. The volume of the granules was large

2. The sachet number of the granules was large

3. Taking granules is harder than tablets regardless of products

4. The tablets taste or smell better than the granules.

5. The tablets are easier to carry than the granules.

6. The other reason

Q III. In case you answered "granules" in 0 I. why?

1. The size of the tablet is big

2. The tablet number is large

3. Taking tablets is harder than granules regardless of products

4. The granules taste or smell better than the tablets

5. The granules are easier to carry than the tablets

6. The other reason

Q V. Which formulation did you feel more effective?

Fig. 2. (A) Questionnaire 1: acceptability of tablets. (B) Questionnaire 2: acceptability of granules. (C) Questionnaire 3: comparison of tablets and granules. All the original questionnaires were written in Japanese. CR, controlled-release. 